\title{
EDUCAÇÃO ESCOLAR EM MOSSORÓ-RN: A CRIAÇÃO DO COLÉGIO DIOCESANO SANTA LUZIA
}

\author{
Francisco das Chagas Silva Souza ${ }^{1}$ \\ Mauro Antonio de Oliveira ${ }^{2}$
}

\begin{abstract}
Resumo
A criação, em 1901, do Colégio Diocesano Santa Luzia, na cidade de Mossoró, é um marco na história da educação do interior do estado do Rio Grande do Norte. Essa instituição formou membros da elite mossoroense e de cidades circunvizinhas que chegaram às esferas do poder local, estadual e nacional. Neste artigo, objetivamos relatar as origens dessa instituição de educação confessional e privada. Realizamos uma pesquisa bibliográfica em obras que abordam o contexto histórico local e nacional em fins do século XIX e princípios do XX, como também nas que tratam especificamente do Colégio Diocesano Santa Luzia. A revisão de literatura nos levou a considerar que a criação dessa escola se deu em função de um cenário local favorável (o crescimento econômico de Mossoró e o fortalecimento de uma elite regional) associado aos interesses da Igreja Católica em controlar a educação, haja vista a crise de hegemonia que sofria em decorrência das mudanças trazidas pela República.
\end{abstract}

Palavras chave: História das Instituições. Educação confessional. Igreja Católica.

\section{SCHOOL EDUCATION IN MOSSORÓ-RN: THE FOUNDATION OF DIOCESANO SANTA LUZIA SCHOOL}

\begin{abstract}
The foundation of Diocesano Santa Luzia School in the city of Mossoró in 1901 is a milestone in the history of education in the countryside of Rio Grande do Norte. This institution graduated members from the elite city and from the surrounding towns who ascended the spheres of local, state and national power. This article aims to report the origins of this confessional and private education institution. A bibliographical study was carried out not only through works that address local and national historical context in the late nineteenth century and early twentieth century, but also as those which specifically talk about the school itself. The bibliographical review revealed that the foundation of this school was due to a favorable local scenario (the economic growth of the city and the strengthening of a regional elite) linked to the Catholic Church interests to control education, considering the hegemony crisis it had been suffering as a result of the changes brought by the Republic.
\end{abstract}

Keywords: History of institutions; Confessional education; Catholic Church.

Desde 2 de março de 1901, quando foi inaugurado, o Colégio Diocesano Santa Luzia, doravante CDSL, tem marcado a história da educação de Mossoró e da região oeste do estado do Rio Grande do Norte. Ao longo de mais de um século de existência, essa escola confessional e privada formou (e ainda forma) grande parte da elite mossoroense que, ainda hoje, detém o poder econômico e político local, estadual e nacional como vereadores, prefeitos, governadores, deputados estaduais, federais e senadores.

A relevância do CDSL para a educação potiguar - mesmo tendo atendido a apenas uma parcela pequena da população, uma vez que se trata de uma instituição privada de ensino - levounos a indagar as razões da sua criação pela Igreja Católica em princípios do século XX, no interior

\footnotetext{
${ }^{1}$ Doutor em Educação (UFRN). Professor do Programa de Pós-Graduação em Educação Profissional (IFRN/Natal) e do Programa de Pós-Graduação em Ensino (UERN/IFRN/UFERSA). E-mail: chagas.souza@ifrn.edu.br

${ }^{2}$ E-mail: mauroant2@hotmail.com
} 
norte-rio-grandense. Considerando que uma instituição de ensino não pode ser estudada de forma isolada, procuramos relacionar as origens dessa escola ao contexto histórico regional e nacional.

Com esse fim, debruçamo-nos sobre a bibliografia acerca da cidade de Mossoró na segunda metade do século XIX. Utilizamos obras que se tornaram clássicas, como as produzidas por Cascudo (2010), Nonato (2010) e Souza (2010), mas também pesquisas mais recentes sobre a história, a economia e o desenvolvimento urbano de Mossoró (PINHEIRO, 2007; ROCHA, 2009). Entretanto, com relação à história da educação em Mossoró, no século XIX, há pouquíssimas informações. Quanto ao CDSL, encontramos apenas uma obra, escrita em 1960 por um dos seus diretores, o cônego Francisco de Sales Cavalcanti. Essa obra nos forneceu vários documentos do acervo dessa escola como a ata de sua criação, discursos, cartas, dentre outros, transcritos na íntegra pelo autor. A procura de uma melhor compreensão do papel da Igreja Católica no sistema educacional, por meio da criação dos chamados colégios diocesanos, conduziu-nos a um conjunto de trabalhos acadêmicos publicados sobre esse tema em periódicos e anais de eventos.

Por fim, importa destacar que este artigo está inserido no campo temático da História da Educação, particularmente, na área da História das Instituições Educacionais, a qual "almeja dar conta dos vários atores envolvidos no processo educativo, investigando aquilo que se passa no interior das escolas, gerando um conhecimento mais aprofundado destes espaços sociais destinados aos processos de ensino e de aprendizagem" (GATTI JÚNIOR, 2002, p. 29). Desse modo, a partir da história das instituições, é possível conhecermos o contexto histórico em que estas foram criadas, que tipo de arquitetura possuíam, que transformações sofreram no seu espaço, qual a rotina de seus alunos, professores e gestores, como estava organizada a estrutura curricular, quais as normas disciplinares, além de vários outros elementos que compõem a vida de uma instituição de ensino (NOSELLA; BUFFA, 2013).

\section{O nascimento do CDSL de Mossoró: buscando nexos}

Para Magalhães (1996), “compreender e explicar a existência histórica de uma instituição educativa é, [...], contextualizá-la, implicando-a no quadro de evolução de uma comunidade e de uma região [...]". Por conseguinte, tencionamos, neste artigo, estabelecer nexos entre as origens CDSL de Mossoró e os cenários históricos local e nacional à época de sua criação, em 1901.

\section{1- Mossoró em fins do século XIX: crescimento econômico e ascensão das elites}

Na segunda metade do século XIX, Mossoró viveu mudanças socioeconômicas e políticas. Os ventos do progresso ali adentraram de modo tal que, entre o final do século XIX e o início do XX, 
essa cidade passou a deter grande visibilidade nas relações comerciais em escalas local, regional e até nacional. Nessa época, já era considerada, como ainda o é hoje, um polo econômico. Sua localização geográfica privilegiada, garantindo "uma boa ligação entre o litoral e o sertão" (ROCHA, 2005, p. 29), era fator essencial para que se tornasse um eixo comercial entre o interior do Rio Grande do Norte e cidades como Aracati e Fortaleza, no Ceará.

Esse desenvolvimento econômico é tema presente nos estudos de vários autores potiguares e deve ser percebido em um conjunto de mudanças econômicas, num cenário bem mais amplo: o da divisão internacional do trabalho, na qual o Brasil entrava como exportador de matérias-primas e importador de produtos industrializados europeus. Ao abordar a economia do Rio Grande do Norte no século XIX, Monteiro (2000) ressalta a importância que teve a Guerra de Secessão, nos Estados Unidos (1860-1865), para o aumento das exportações nessa província. A redução das exportações norte-americanas de algodão para suprir o mercado europeu proporcionou uma demanda por esse produto que logo seria preenchida pelo nordeste brasileiro.

Contando com um porto de escoamento de mercadorias, o porto de Areia Branca, aberto em 1867, “[...] Mossoró se tornou um importante centro comercial na província, principalmente do comércio algodoeiro. Para lá passaram a convergir mercadorias não só de todo o oeste potiguar, mas também de partes do Ceará, sertão da Paraíba e região do Seridó” (MONTEIRO, 2000, p. 134). Portanto, esse surto exportador deu a Mossoró uma forte relevância nas relações comerciais em níveis estadual e regional, mantendo posição que já detinha em função de outras atividades como a pecuária.

Pinheiro (2007), ao estudar a expansão urbana em Mossoró, relaciona esse processo às diversas especializações econômicas pelas quais passou essa cidade: a pecuarista, o empório comercial, a salicultura, a agroindústria e a prestação de serviços. Em função do nosso recorte temporal, daremos destaque à fase do empório comercial.

Segundo Pinheiro (2007, p. 46):

Os anos entre 1850 e 1870, do ponto de vista econômico, foram anos de um intenso desenvolvimento comercial na província, com o estabelecimento de comerciantes, principalmente estrangeiros, que trabalhavam com a importação de produtos manufaturados europeus e exportação de matérias-primas locais, como algodão, couro e sal para o mercado externo.

A instalação de comerciantes estrangeiros em Mossoró, no século XIX, é ressaltada por praticamente todos os pesquisadores que estudam a sua história. Para Nonato (2010), a expansão comercial nessa cidade, à época, é verificada pelas inúmeras firmas que ali se estabeleceram. Na obra "Negociantes \& Mercadores", ele faz registros de vários estabelecimentos inaugurados em 
Mossoró nesse período, dentre os quais a Casa Graff, Conrado Mayer, Casa Mossoró \& Cia e Wilhelm Deffren, além de outras.

Esse crescimento econômico logo provocou uma expansão do espaço urbano (ROCHA, 2009; PINHEIRO, 2007) e influenciou em nível político (MONTEIRO, 2000). Em 1852, o núcleo populacional foi elevado à categoria de vila e desmembrado da Vila da Princesa, da comarca de Açu, por meio da Lei n. 246, de 15 de março de 1852. Mais tarde, em 9 de novembro de 1870, ou seja, no auge da fase em que era um empório comercial, a Vila de Santa Luzia foi elevada à cidade, por meio da Lei n. 260.

Entretanto, a fase do empório comercial foi marcada também por crises conjunturais, como a grande seca de 1877-1879. Apesar dos relatos sobre essa seca enfatizarem o seu caráter catastrófico, para alguns pesquisadores, a exemplo de Nonato (2010), Souza (2010), Rocha (2005) e Braz (1999), ela não chegou a abalar de forma contundente a economia local. Pelo contrário, essa estiagem possibilitou o crescimento de alguns setores do comércio mossoroense, uma vez que muitos comerciantes locais conseguiram apoio do governo para vender alimentos às vítimas, os chamados "flagelados da seca", beneficiando-se em virtude dos altos preços cobrados.

Além disso, a maioria desses indivíduos que sofreram diretamente os efeitos da seca foi aproveitada no trabalho em obras públicas, como a construção da cadeia pública municipal e de estradas, e ainda no trabalho nas salinas e no comércio. Era uma manifestação clara da "indústria das secas", tão conhecida pela população do semiárido nordestino, como estudaram Souza e Medeiros Filho (1984).

Assim, a partir da discussão ora apresentada, podemos compreender que o cenário mossoroense em fins do século XIX, marcado pelo desenvolvimento das atividades comerciais e pela consequente formação de uma classe social abastada, era propício para a instalação de uma escola na qual essa elite regional pudesse formar os seus filhos, daí o seu empenho nesse sentido, como veremos adiante. O papel desempenhado pela Igreja Católica foi fundamental para que isso ocorresse.

\section{Educação e romanização: nasce uma escola confessional em Mossoró}

A história da educação em Mossoró, sobretudo aquela que diz respeito ao século XIX, carece de investigação acadêmica. Os poucos registros existentes são superficiais e contraditórios, deixando-nos com mais dúvidas que informações sobre esse tema. 
Souza (2010) nos informa que, no início do século XIX, existiam duas escolas diurnas de ensino primário, divididas para os gêneros masculino e feminino. Mais tarde, com a Proclamação da República, outras escolas são criadas em Mossoró:

[...] a Intendência criou escolas mistas do ensino primário nos Povoados de Santo Antonio, São Sebastião, Santana, Macambira, mantendo atualmente a mesma Intendência somente as seguintes: duas na cidade, sendo uma para cada sexo; 4 mistas, sendo uma no Porto Santo Antônio, sendo no Alto da Conceição, uma em São Sebastião e uma outra no Rincão (SOUZA, 2010, p. 29-30).

Moura (1995) faz referência a uma escola de ensino secundário, fundada em 1900, denominada Colégio Sete de Setembro, com o qual "ficou implantado o ensino nessa cidade" (p. 62, grifo nosso). Mas, conforme esse autor, em 1903, em decorrência de uma seca, o fundador dessa escola, o Prof. Antonio Gomes de Arruda Barreto, transferiu-a para a atual cidade de MartinsRN. Em outra fonte, encontramos que essa instituição era a única do interior do Rio Grande do Norte a preparar alunos para os chamados exames finais, realizados no Colégio Atheneu, em Natal (OS MESTRES..., 2007, p. 4).

Certamente, o Colégio Sete de Setembro não “implantou o ensino” em Mossoró, como afirmou Moura (1995). É quase impossível que uma cidade com aquele porte não possuísse escolas, mesmo que fossem nas residências de professores e professoras que levavam o conhecimento das primeiras letras às crianças em troca de uma mensalidade, algo tão comum naquele tempo. Como registra Alves (2009), a expansão do ensino privado dava-se devido ao "estado de abandono" do público: "a ausência de recursos das Províncias para organizar seu próprio ensino, público e gratuito, especialmente em nível secundário, abriu espaço para que a iniciativa privada assumisse tal tarefa" (p. 74).

A precariedade da educação formal em Mossoró, mesmo sendo esta uma cidade cuja elite já participava de uma loja maçônica, criada em 1873, instalou nesse setor da sociedade o desejo de incorporar seus filhos à "“classe dos homens letrados', habilitados a preencher determinadas funções sociais" (ALVES, 2009, p. 74).

Conforme Sousa (2009, p. 3-4), era uma elite que

[...] pretendia não apenas ser bem-sucedida economicamente, mas também pretendia encarnar aquele grupo que melhor compreensão detinha do lugar, do seu espaço, e que melhores propostas possuía para desenvolvê-lo, escudadas no exemplo de outros povos, traduzido por seus pensadores, escritores, poetas e políticos. O ambiente do final do século XIX, reunindo comerciantes e empresários de várias nacionalidades, homens que carregavam consigo as informações de sua época, um certo conhecimento da história, da literatura, e, sobretudo, uma perspectiva de mundo, alimentada nos ideais iluministas e positivistas, favorecia a 
criação de uma vocação para o lugar, uma destinação para o seu povo (SOUSA, 2004, p. 3-4).

Consoante Alves (2009), a má qualidade da escola pública e o entendimento da sociedade de que a escola particular lhes oferecia perspectiva educacional culturalmente enriquecida, universalizada e prenhe de valores liberais são algumas das razões para a expansão das escolas confessionais, presentes no Brasil desde a colonização. Naquela época, imbuídos de papel de instruir, os jesuítas educavam, preferencialmente, "os membros das famílias mais aquinhoadas financeiramente ao ministrar-lhes um ensino do tipo clássico, humanístico, literário, acadêmico e abstrato, conforme o ideal da época" (ALVES, 2009, p. 72).

Como em tantas cidades brasileiras, a sociedade mossoroense via a Igreja Católica como um símbolo de respeito e confiança. A criação de uma escola, em Mossoró, sob a égide dessa instituição era ideal para um grupo desejoso de um modelo de educação que representasse seus interesses, fornecesse-lhe "cultura" e o mantivesse no poder. Esse interesse facilitou a implantação do CDSL, conforme encontramos na narrativa do cônego Francisco de Sales Cavalcanti.

Importa destacar que o Cônego Francisco de Sales Cavalcanti foi diretor do Colégio Diocesano Santa Luzia no período de 1946 a 1957. É o autor da obra Apontamentos sobre a história do Colégio Diocesano Santa Luzia de Mossoró, publicada em 1960, principal fonte para os pesquisadores da história dessa instituição de ensino, haja vista que muitos registros foram perdidos ou estão em arquivos particulares. O livro do Cônego Cavalcanti, com mais de 400 páginas, "preenche" algumas lacunas deixadas pela ausência ou dificuldade de acesso a essas fontes de pesquisa, haja vista que o seu autor transcreveu, na íntegra, documentos importantes, como a ata de inauguração da escola, relações de alunos de várias turmas, normas de funcionamento, listas e horários das disciplinas, dados biográficos dos seus diretores, termos de visitas, livros de receitas e despesas, dentre outras informações importantes para os historiadores da educação. Além disso, por ter sido escrito em fins da década de 1950, conseguiu entrevistar alguns ex-alunos das primeiras turmas.

Com uma linguagem eloquente e laudatória, o cônego Cavalcanti inicia seu relato apresentando sua concepção de educação: “[...] a chave de ouro que nos abre o enigma da vida, traçando-nos a vereda dos nossos destinos e, por isso, aquêle que educa, apostoliza o homem, apostoliza as sociedades para a felicidade e a glória infindas da imortalidade.” (1960, p. 18, sic). Em seguida, convida o leitor a se curvar diante de um "vulto venerando" que "sentiu profundamente as palpitações calorosas do coração generoso da pequena parcela do seu rebanho [...]". Esse vulto era o "Exmo. e Revmo. Sr. Dom Adauto Aurélio de Miranda Henriques, de imperecível memória, 
digníssimo e incansável Bispo de uma imensa Diocese que, naquele tempo, compreendia os Estados da Paraíba e do Rio Grande do Norte.” (CAVALCANTI Cavalcanti)

Dom Adauto foi nomeado, em 1892, bispo da Diocese da Paraíba, à qual a Igreja Católica do Rio Grande do Norte estava ligada. Ele foi, segundo o cônego Cavalcanti, uma peça essencial para a criação do CDSL um ano após a sua primeira visita pastoral a Mossoró, em 30 de janeiro de 1900. Os fiéis, ávidos para ouvir a palavra do bispo, segundo o cônego Cavalcanti (1960, p. 19), era “[...] uma gente formada à sombra dos ensinamentos cristãos”. O bispo, nos seis dias que passou em Mossoró, "auscultou as aspirações mais íntimas dos seus diocesanos". Uma delas "lhe tocou mais fortemente o coração": o desejo dos mossoroenses de possuírem uma escola de orientação católica (CAVALCANTI, 1960, p. 19).

Diante disso, Dom Adauto, "junto aos cidadãos de maior projeção na terra" (grifo nosso), discutiu a possibilidade de instalação, já no ano seguinte, "de um educandário que viesse preencher os requisitos mais indispensáveis à formação dos môços não sòmente quanto à cultura intelectual, de modo geral, mas especialmente quanto aos princípios cristãos e católicos" (CAVALCANTI, 1960, p. 19). De acordo com o autor, a proposta da criação do CDSL foi apresentada, pelo bispo, nos seus sermões na Igreja Matriz de Santa Luzia.

Como não poderia ser diferente, as famílias mossoroenses, "representadas pelos seus homens de comércio e indústria, citadinos e sertanejos" (Grifo nosso), apoiaram a proposta do bispo e logo iniciaram as articulações para que a fundação do colégio ocorresse no menor tempo possível. Em vista disso, formou-se uma comissão para adquirir prédio e mobiliário para a funcionamento da escola. Conforme a narrativa do cônego Cavalcanti (1960), essa comissão foi composta por homens de grande projeção social, econômica e política na cidade: o juiz de direito da Comarca de Mossoró, um "alto comerciante e grande capitalista" e um médico, "ilustre político de invulgar prestígio". Ou seja, fica muito claro no texto do ex-diretor do Colégio Diocesano a quem a criação dessa escola interessava e a qual grupo social ela era endereçada.

Em razão da receptividade da população, Dom Adauto, ao retornar à sede da Diocese, na Paraíba, leva consigo a esperança de realização de sua promessa de criar "uma educação moldada nos princípios evangélicos, fator máximo da felicidade dos povos" (CAVALCANTI, 1960, p. 19).

A comissão formada logo iniciou a busca para angariar os fundos necessários à aquisição de prédios onde seria instalada a escola. Foram adquiridas cinco casas no centro da cidade, próximas à Igreja Matriz, destinadas à futura construção do colégio. Segundo o cônego Cavalcanti (1960), como os registros desses imóveis foram extraviados nos cartórios, não há certeza se houve compra de todas essas casas ou doação de algumas delas pelos seus proprietários. Estava, assim, "lançada a 
primeira semente, [...] o primeiro esteio do grande 'colégio' do futuro. Aquelas casas humildes [...] se transformariam em possantes raízes de uma frondosa árvore de cultura nas terras férteis do Rio Grande do Norte" (CAVALCANTI, 1960, p. 20-21).

Uma leitura mais atenta do texto escrito pelo cônego Cavalcanti nos conduz a uma pergunta: de quem partiu a ideia de criar o CDSL? A nosso ver, há uma contradição no relato do religioso, pois, inicialmente, este afirma que um desejo dos mossoroenses "tocou o coração" de Dom Adauto. Essa aspiração era a criação de uma escola confessional. Adiante, destaca que, em seus sermões, o bispo "abordou o assunto, fazendo uma exposição ao povo de sua idéia e pedindo o apoio de todos" (1960, p. 19, grifo nosso). Ou seja, não fica claro de quem partiu essa intenção. Contudo, um estudo do contexto histórico da época nos leva a crer que havia uma conjugação de interesses, tanto da população mossoroense (leia-se uma burguesia em ascensão e carente de uma escola que correspondesse ao seu nível social), quanto da Igreja, que procurava reagir a um conjunto de mudanças advindas da instalação do regime republicano no Brasil. Sobre esse aspecto, achamos apropriado fazer uma breve digressão.

No último quartel do século XIX, a Igreja Católica sofreu diversos reveses. A chamada "Questão Religiosa" foi um dos maiores, pois colocou em xeque as relações entre a Igreja e a Monarquia. A proclamação da República, em 1889, e o Decreto 119-A, de 7 de janeiro de 1890, determinando o fim do Padroado e o estabelecimento da liberdade de culto no Brasil terminavam um período de quase quatro séculos do catolicismo como religião oficial do Estado, quando a Igreja tinha a garantia de certas prerrogativas típicas do Antigo Regime, embora com liberdade limitada.

Apesar disso, conforme Nagle (2009), a instalação do regime republicano no Brasil não foi recebida de forma traumática pela Igreja. Muitos de seus expoentes chegaram a salientar a liberdade que teriam com o fim do Padroado. Assim:

Afora um ou outro acontecimento que não chegaram a definir uma "questão religiosa", os dois primeiros decênios do regime republicano devem ser caracterizados como de calmaria no meio católico. Apenas durante a terceira década se esboçam as primeiras manifestações mais importantes, que eclodirão no decênio seguinte sob a forma de chamamento geral (NAGLE, 2009, p. 72).

Mesmo sem se opor diretamente, a Igreja não ficou de braços cruzados. Diante das mudanças impostas pelo novo regime, os bispos se posicionaram, em março de 1890, por meio da primeira Carta Pastoral Coletiva do Episcopado Brasileiro. Esse documento estabelecia algumas estratégias de reação à perda de prestígios e de poder da Igreja. Uma delas era a criação de dioceses. Assim, para Aquino (2012, p. 58-59): 
[...] a diocesanização do catolicismo no Brasil, como parte de um movimento internacional de reorganização da ICAR [Igreja Católica Apostólica Romana], apresentou-se na condição de estratégia eclesiástica fundamental para ampliar a presença eclesiástica na sociedade brasileira, respondendo às demandas da Cúria Romana e às necessidades sociopolíticas e religiosas específicas de cada unidade federativa da República brasileira. A diocesanização indicou ainda a ambígua e tensa relação da ICAR com a modernidade, afinal, ela incorporou muitas de suas novidades científicas e tecnológicas, mas combateu as suas repercussões morais e religiosas.

A diocesanização teve início com a criação das dioceses da Paraíba, Amazonas, Curitiba e Niterói pelo papa Leão XIII, em 27 de abril de 1892, elevando o número delas de 12 para 16. Dom Adauto, um dos personagens de destaque nesse conjunto de ações que a Igreja viria a desenvolver, foi nomeado bispo da Paraíba em 1894.

Também em 1890, Dom Antonio de Macedo Costa, bispo de Belém, redigiu um documento intitulado "Alguns pontos de reforma da Igreja no Brasil", o qual circulou apenas entre os seus pares e só foi dado a público em 1949. Esse texto, de apenas vinte páginas e nove capítulos, era um documento pragmático e ia ao encontro do movimento de controle do papado sobre a Igreja Católica no Brasil durante o século XIX. Por isso, é visto como a súmula do processo de romanização do catolicismo brasileiro (MESQUIDA; LORENZETTI, 2001; MESQUIDA, 2001).

Conforme já havia feito antes, em 1874, Dom Macedo, no seu texto de 1890, reafirma a necessidade de reformar a Igreja. Para isso, conclamou todas as dioceses para "restaurar a disciplina do Clero, sanar males, reformar abusos, dar todo o decoro e lustre ao culto de Deus [...]" (MACEDO COSTA, 1982 apud MESQUIDA; LORENZETTI, 2001, p. 61).

Mesquida (2001, p. 8) comenta o porquê da convocação feita pelo bispo de Belém:

Encontramos, no período, duas igrejas: uma, clerical, burocrática, pastoralmente debilitada e, outra, laica, ativa, popular. Esta, cultuava os santos e se expressava por meio das confrarias e irmandades e das lideranças leigas (ermitões e beatos que se dedicavam à vida ascética e perambulavam pelo interior, rezando, benzendo, batizando, vistos pelo povo como homens santos). Os leigos realizam festas religiosas, procissões, lideravam as novenas, as rezas do terço, as ladainhas. Tratava-se de uma "igreja" de "muita reza e pouca missa, muito santo e pouco padre", de um catolicismo mágico, "carismático" (no sentido weberiano), com efeitos de natureza meteorológica (reza para que chova ou faça sol, etc.), terapêutica (cura por meio da reza ou das benzeduras), divinatória, e que não necessita do sacerdote: qualquer pessoa pode ser portadora da "gratia infusa".

Diante desse quadro, Dom Macedo, no $7^{\circ}$ capítulo de "Alguns pontos de reforma da Igreja no Brasil", apresentou a fundação de escolas como um elemento central para essa reestruturação. Eralhe necessário “[...] evitar às famílias católicas a dura necessidade de, por falta de escolas e colégios para seus filhos enviarem-nos a colégios protestantes [...]. Devem ser trazidas da Europa 
congregações religiosas, masculinas e femininas, para fundar escolas e dirigir o ensino dos católicos [...]" (MACEDO COSTA, 1982 apud MESQUIDA; LORENZETTI, 2001, p. 62, grifo nosso).

A preocupação com a expansão das instituições escolares de orientação protestante era procedente, haja vista que já existiam duas em São Paulo (OLIVEIRA, 2010). Com o Decreto 119A, de 1890, e o consequente estabelecimento da liberdade de culto, abria-se a possibilidade da criação de mais dessas escolas, o que de fato ocorreu como nos mostra Oliveira (2010, p. 157). Para essa autora, "[...] o protestantismo tornou-se uma verdadeira provocação aos ensinamentos católicos e a reação católica foi de restaurar seus princípios, também, por meio de suas escolas e colégios, além de um elenco de ações que abrangeria todos os segmentos sociais" (2010, p. 149).

Portanto, pari passu à instrução escolar, assumida pelo Estado republicano, o clero católico, com apoio da Santa Sé, esforçou-se em construir estabelecimentos de ensino como parte de suas atividades pastorais. Era uma forma de garantir ou recuperar a hegemonia social abalada com a República.

A catequese escolar tornou-se a estratégia mais importante da romanização. Conforme Mesquida (2001, p. 14), os bispos reformadores, signatários da Pastoral Coletiva de 1890, tinham uma visão bíblico-teológica do "divini magisteri” da Igreja. Expressa a Pastoral: "O ensino da igreja será para todos a regra imediata de fé, e quem não ouvir a Igreja, disse Jesus, segundo o Evangelho de Mateus, 18.17, e Lucas 10.16, seja tido como pagão e publicano, pois quem a ouve, a mim me ouve". Por isso, "Ide e ensinai a todas nações, e eis que estarei convosco todos os dias até o fim dos séculos".

Na opinião de Mesquida (2001), a missão educativa se efetuou junto à elite, em particular a urbana, atraindo-a para as hostes da Igreja e preparando-a para exercer influência junto às autoridades constituídas. Convém destacar que as instituições escolares católicas só ganharam um status representativo graças à credibilidade dada a elas pelas camadas sociais abastadas. Tanto o é que, quando se observa como são fundados alguns colégios diocesanos na transição do século XIX e XX, tem-se as elites locais como abraçadoras de tal causa, fato que ocorreu em Mossoró, conforme o relato do Cônego Cavalcanti (1960).

Desse modo, visto em uma perspectiva macro, é possível compreender porque, para Dom Adauto, a criação do CDSL, em uma cidade com posição estratégica como Mossoró, seria um excelente instrumento, não apenas para a propagação da religião católica, mas, também, para exercer um controle sobre as ideias por meio da educação. 
Há de se convir que dois "perigos” para a Igreja já eram visíveis nessa cidade: a Maçonaria, instalada desde 1873, e o avanço protestante. No que tange à primeira, sua criação foi acompanhada de imbróglios, como relata Souza (2010, p. 154-155):

[...] foi criada em Mossoró, em 1873, uma Sociedade Maçônica denominada "24 de Julho". [...] pelo que provocou a criação da Loja Maçônica "24 de Julho" uma forte repulsa por parte dos católicos e do Pároco que manifestou-se inimigo dessa instituição desde a instalação da Loja, até deixar de curar a Freguesia, pois era fiel cumpridor das ordens do seu Prelado Diocesano. [...] Pondo em execução essas ordens do Bispo de sua Diocese, o Padre Antonio Joaquim provocou os ânimos dos maçons de "24 de Julho", que em Mossoró abriram luta atacando-o pela imprensa representada pelo "O Mossoroense" daquela época, já em artigos, já em discursos publicados.

Em páginas seguintes, Souza (2010) destaca que o conflito entre a Igreja Católica mossoroense e a Loja Macônica chegou ao ponto do padre Antonio Joaquim "inimigo irreconciliável de Maçonaria" recusar-se a casar maçons "sem que primeiro estes se confessassem, abjurando suas crenças" (SOUZA, 2010, p. 156).

Quanto à chegada do protestantismo em Mossoró, a literatura dá conta de que, a partir de 1883, Mossoró era visitada por missionários presbiterianos. Souza (2010, p. 122-123) destaca a passagem do americano Dr. De Lacy Wandlaw: "Esse ministro demorando-se alguns dias em Mossoró fizera diversas conferências, assistidas por um sempre crescente número de ouvintes, alguns dos quais aceitaram a religião evangélica". A população mossoroense, majoritariamente católica, reagiu: "Muitos fanáticos e alguns desocupados, sem crença alguma, a horas mortas da noite, apedrejaram as casas de residência dos evangelistas de maneira selvagem e desumana" (SOUZA, 2010, p. 123). Também Cascudo (2010, p. 130) comenta a respeito de uma escola dominical fundada pelo Rev. Wardlaw "e que era concorrida. Contavam mais de cinquenta protestantes e o pastor vinha de Fortaleza sempre oficiar em casamentos e batizados".

Baseado na divisa iter para tutum, ou seja, "cuidai para que meu caminho seja seguro", retirada de uma antiga oração dos navegantes dirigida à Virgem Maria (KULESZA, 2002), Dom Adauto desenvolveu incansavelmente sua luta. Segundo o cônego Cavalcanti (1960, p. 350), esse bispo "fundou 13 colégios, erigiu 19 novas paróquias, realizou quase 200 visitas pastorais, ordenou 140 padres, numa presença onímoda que trabalhava e fazia trabalhar”3.

Diante desses esforços, o CDSL, conhecido em seu nascedouro como Educandário Santa Luzia, abriu suas portas em 2 de março de 1901, com um total de 59 alunos matriculados, dos quais

\footnotetext{
${ }^{3}$ Sobre as ações de D. Adauto no processo de romanização da Igreja, sugerimos as leituras de Kulesza (2002), Dias (2008) e Barreto (2009).
} 
14 eram internos e 45 externos. Do total de 59, 42 estavam matriculados no curso primário e, 17, no secundário (CAVALCANTI, 1960).

A solenidade de inauguração contou com a presença de vários membros da Igreja e da alta sociedade local, como podemos ver no texto da ata que trata dessa sessão:

[...] reunidos os cidadãos abaixo assignados, sob a presidencia do Reverendíssimo Cônego Estevam José Dantas, com a assistencia do Reverendo Vigário João Urbano d'Oliveira, Doutor João Dionysio Filgueira, Juiz de Direito desta circumscripção, Doutor Francisco Pinheiro d'Almeida Castro, ilustre facultativo desta cidade, Coronel Antonio Gomes d'Arruda Barreto, Director do Collegio "Sete de Setembro" [...] (CAVALCANTI, 1960, p. 22).

Na solenidade, de acordo com a ata, o cônego Estêvão José Dantas, diretor da escola ora em inauguração, diz, em seu discurso, que vem, em nome de Dom Adauto, "fundar e dirigir um Collegio de instrucção primaria e secundaria, a par da educação moral e religiosa". Em seguida, explica o motivo da escolha daquela data: "dia que comemmorava o anniversario natalício do grande Pontifice que rege os destinos do povo christão, nesta quadra de grandes difficuldades para a sociedade em geral e para a Egreja em particular". (Grifo nosso)

O cônego Estêvão José Dantas, primeiro diretor do CDSL, chegou a Mossoró em 22 de fevereiro de 1901. Ele é descrito pelo cônego Cavalcanti como um representante do bispo diocesano para: “[...] dirigir um Colégio de instrução primária e secundária que, além das letras, ministraria aos môços desta terra e dos Estados visinhos, a formação moral, cívica e religiosa, como valioso e imprescindível complemento àquele progresso material que se esboçava dos mais promissores para a esta região [...]" (1960, p. 21). A alusão feita aqui, pelo autor, à economia local é retomada na página seguinte: "Por si mesmas, as atividades comerciais não constituem o todo, mas uma das modalidades de progresso humano que não prescinde, em absoluto, desta outra forma de atividade: a cultura intelectual, tanto profana como religiosa". Portanto, o CDSL vinha para completar o outro lado da moeda.

A administração do cônego Estevão contou com o auxílio do diácono Pedro Paulino Duarte da Silva e de João Ferreira da Silva, este último desempenhando as funções de prefeito de alunos (CAVALCANTI, 1960, p. 23). A existência desse cargo evidencia a forte influência da pedagogia jesuítica, cuja base encontrava-se no Ratio Studiorum, um plano geral de estudos implantado nos colégios da Ordem da Companhia de Jesus, no início da colonização. Era, esse prefeito, um auxiliar do reitor na ordenação dos estudos, devendo ser obedecido pelos alunos e professores. "Explicitase, pois, no Ratio Studiorum, a ideia de supervisão educacional”, segundo Saviani (2010, p. 56).

Como considera Kulesza (2002, p. 2), “[...] os soldados de Cristo não eram simplesmente uma remota lembrança dos tempos coloniais: eles estavam presentes no cotidiano de nossas escolas.”. 
Dom Adauto, o fundador do CDSL, recebeu uma formação jesuíta. Foi sagrado bispo na capela do Colégio Pio Latino-Americano, em Roma, instituição na qual havia concluído seu doutorado em direito canônico e que era dirigida pela Companhia de Jesus.

No que tange ao que denominamos cultura escolar - "um conjunto de normas que definem conhecimentos a ensinar e condutas a inculcar, e um conjunto de práticas que permitem a transmissão desses conhecimentos e a incorporação desses comportamentos” (JULIA, 2001, p. 10) -, o cônego Cavalcanti, com base em documentos arquivados no CDSL e em relatos orais de exalunos das primeiras turmas, revela algumas práticas do cotidiano dessa instituição nos seus primeiros anos de funcionamento.

Como não poderia ser diferente em uma escola confessional católica, a influência religiosa permeava o dia a dia de alunos e professores. A presença das orientações do Ratio Studiorum confirma isso.

A abertura do ano letivo, ocorrida sempre no dia 2 de março, data em que se comemorava o aniversário da escola, era realizada com uma missa "celebrada pelo Diretor, precedida do hino de invocação do Espírito Santo”, conta o cônego Cavalcanti (1960, p. 34). Os alunos deveriam participar, uniformizados, de todas as festas cívicas, a exemplo dos desfiles no dia 30 de setembro ${ }^{4}$, e religiosas, sobretudo as cerimônias da Semana Santa na Igreja Matriz de Santa Luzia. As aulas de catecismo ficavam a cargo do diretor e estavam presentes entre as disciplinas ministradas, de acordo com o horário das aulas transcrito pelo cônego Cavalcanti.

No "Colégio dos padres", como ficou conhecido popularmente o CDSL, tratavam-se com rigor as normas de comportamento. Embora o cônego Cavalcanti não tenha se preocupado em fazer um detalhamento das regras, interdições e sanções impostas aos alunos, ficam implícitas, no seu relato, situações em que estes deveriam comparecer ou caminhar "em forma", ou seja, perfilados em linhas. Contudo, talvez para atenuar a rigidez da disciplina na instituição, o autor diz que "os alunos internos não eram prisioneiros. Tinham o seu passeio semanal, às quintas-feiras de tarde. Saíam do Colégio em forma, dois a dois, [...] e se distraíam, brincavam à vontade ao ar livre dos campos" (CAVALCANTI, 1960, p. 27).

Pelo que vemos no texto do cônego Cavalcanti, o mal comportamento era punido com castigos morais como o isolamento ou proibição de participar da recreação e de outros momentos de lazer. Porém, apesar desse rigor, o cônego Cavalcanti narra situações em que as normas eram quebradas pelos jovens nas descontrações com os colegas e, até mesmo, com os padres.

\footnotetext{
${ }^{4}$ Mossoró se apresenta como a primeira cidade no Brasil a abolir a escravidão, fato que ocorreu no dia 30 de setembro de 1883. Apesar das controvérsias geradas em torno desse pioneirismo (BRAZ, 1999), Mossoró se autodenomina a "Terra da Liberdade" e lembra essa data, todos os anos, com desfiles cívicos e ampla participação das escolas e da sociedade.
} 
Não se tem informações sobre a existência de castigos físicos, como o uso da palmatória. Entretanto, outros métodos, além dos castigos morais, eram empregados para se conseguir a tão almejada disciplina e a produtividade dos alunos do CDSL. Um deles consistia em premiar os melhores alunos, certamente aqueles que tinham bom comportamento e se sobressaíam nos exames. O cônego Cavalcanti relata, em várias passagens do seu livro, as solenidades de encerramento do ano letivo, nas quais, diante da família e da sociedade mossoroense, havia discursos e a entrega de medalhas "que ornamentavam as lapelas dos bravos generais das letras" (1960, p. 31).

Em relação às instalações do CDSL, não faltam expressões do cônego Cavalcanti salientando as dificuldades em que se encontrava o prédio original. Era, no seu início, "um Colégio paupérrimo, existindo exclusivamente pela boa vontade da Igreja e do povo generoso e piedoso de Mossoró" (1960, p. 27). A precariedade da escola era tamanha que o Frei Rolim, um dos seus diretores, chegou a afirmar que "o Santa Luzia é [...] um pardieiro de ciganos, sem piso, sem embuço, sem futuro" (CAVALCANTI, 1960, p. 54). As reformas só viriam no decorrer dos anos. Em 1956, deuse a inauguração do novo prédio do CDSL (FIG. 1).

\section{Figura 1 - Prédio do CDSL (1956)}

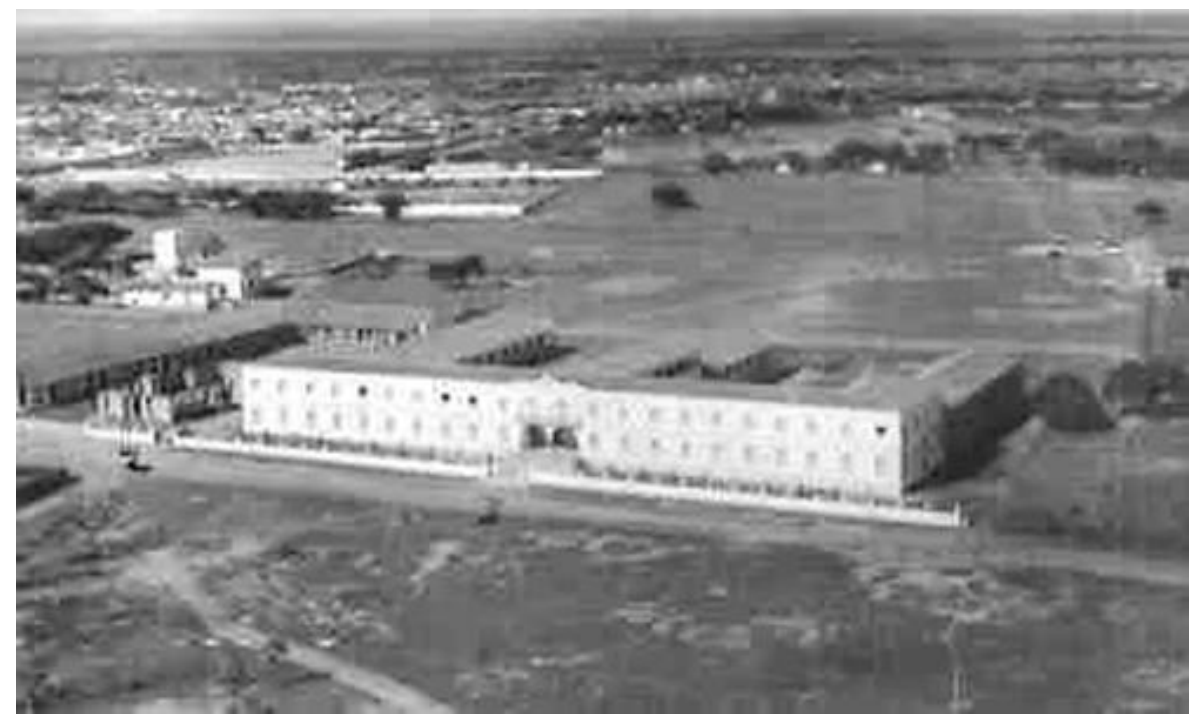

Fonte: Sítio do CDSL - Disponível em: http://cdsl.com.br/o-diocesano/sobre-o-diocesano/. Acesso em: $22 \mathrm{dez} .2015$.

Às dificuldades das instalações iriam se somar outras, relacionadas à gestão e à carência de professores. Em 1906, em função de problemas de saúde, o cônego Estevão, então diretor do CDSL, entregou a direção dessa escola ao Pe. Francisco Hermenegildo de Lucena Sampaio. Entretanto, este, atendendo ao chamado de Dom Adauto, na Paraíba, foi substituído pelo Pe. Pedro Paulino Duarte da Silva. Este, em 1907, considerando o fato de ser o cristianismo "uma religião educadora e não podia essa educação limitar-se aos mais abastados" (CAVALCANTI, 1960, p. 40), passou a 
ofertar uma turma do ensino primário, noturna e gratuita, aos que não tinham condições financeiras para pagar as mensalidades.

O número de matrículas permaneceu numa média anual de 75 alunos. No entanto, a partir de 1907, verificou-se uma queda vertiginosa nas matriculas (54 alunos em 1907; 43, em 1908; 27, em 1909), talvez devido à instabilidade gerada pelas mudanças de diretores. A carência de professores torna-se mais grave em 1908, quando Dom Adauto informa não dispor de padres suficientes para as paróquias e a direção dos colégios. A falta de pessoas para ajudar na disciplina foi motivo para o fim do semi-internato e do internato, em 1908.

As dificuldades se tornaram insustentáveis e, em 1909, apesar do desejo de manter o funcionamento do CDSL, seu diretor decide fechar as portas dessa escola. Assim, por três anos, de 1909 a 1911, essa instituição esteve com suas atividades suspensas, reiniciando-as em 1912. As mudanças constantes de diretores também ocorreram entre 1912 e 1922 . Neste ano, houve apenas 25 matrículas depois de vários anos seguidos com um número alto, numa média de 90.

Os motivos dessa queda são desconhecidos, segundo o cônego Cavalcanti: "Não consegui nenhum roteiro, apesar de haver muito cuidadosamente procurado em todos os jornais da época, ao meu alcance e entre os alunos de então" (1960, p. 72). Esse declínio motivou o fechamento do CDSL, em 1922, reabrindo em 1924, com 157 alunos, mantendo-se em funcionamento até a atualidade.

\section{Considerações Finais}

Neste artigo, apresentamos e discutimos os resultados de uma pesquisa bibliográfica cujo objetivo foi conhecer as origens e os primeiros anos de funcionamento do Colégio Diocesano Santa Luzia (CDSL), em Mossoró-RN, em 1901.

A partir de uma produção acadêmica acerca da economia mossoroense de fins do século XIX e princípios do XX, como também de informações apresentadas pelo Cônego Francisco de Sales Cavalcanti, que levou para a sua obra toda a documentação dos arquivos do CDSL, podemos concluir que essa instituição de ensino cumpriu a função para a qual foi criada: educar as elites e evangelizar. Em outros termos: veio assegurar o poder político e ideológico da Igreja Católica na região oeste do Rio Grande do Norte.

No seu mais de um século de existência, escolarizou "figuras ilustres" do oeste potiguar e de estados vizinhos, como a Paraíba e o Ceará. Em 2001, na celebração do centenário dessa escola, o seu ex-diretor, o Pe. Sátiro Cavalcanti Dantas, salienta esse fato: "Daqui saíram sete governadores, 
seis do nosso Estado e um da Paraíba, o João Agripino, senadores, deputados, prefeitos, nem se conta. Estas carnaúbas plantadas do lado de fora, cada uma representa um ex-aluno governador".

Acrescenta ainda o religioso que "o colégio tem a sua história na medicina, na advocacia, no comércio, nas prefeituras, etc. Atualmente, quase todos os vereadores de Mossoró estudaram no Diocesano e os que não o fizeram, são pais de alunos". Os destaques dados pelo Pe. Sátiro confirmam o quão positivo foi a presença do CDSL para a elite política e econômica de Mossoró e da região. Evangelizou, reforçou o poder da Igreja e educou os filhos das classes abastadas que chegaram ao poder e ali se mantêm.

\section{Referências}

ALVES, Manoel. A histórica contribuição do ensino privado no Brasil. Revista eletrônica da PUCRS, Porto Alegre, v. 32, n. 1, p. 71-78, jan./abr.2009.

AQUINO, Maurício de. Modernidade republicana e diocesanização do catolicismo no Brasil: as relações entre Estado e Igreja na Primeira República (1889-1930). Revista Brasileira de História, São Paulo, v. 32, n. 63, p. 143-170, jun. 2012.

BARRETO, Raylane Andreza D. N. A formação de padres no nordeste do Brasil (1894-1933). 2009. 241f. Tese (Doutorado em Educação) - Universidade Federal do Rio Grande do Norte. Natal.

BRAZ, Emanuel Pereira. A abolição da escravidão em Mossoró: pioneirismo ou manipulação do fato. Mossoró: Fundação Vingt-un Rosado, 1999.

CASCUDO, Luís da Câmara. Notas e documentos para a história de Mossoró. 5. ed. Mossoró: Fundação Vingt-un Rosado, 2010.

CAVALCANTI, Francisco de Sales. Apontamentos sobre a história do Colégio Diocesano Santa Luzia de Mossoró. Rio de Janeiro: Irmãos Pongetti Ed., 1960.

DANTAS, Sátiro Cavalcanti. Colégio Diocesano: um século de glórias. Entrevista concedida a Eduardo Thomé. O Mossoroense, Mossoró-RN, 25 fev. 2001. Disponível em:

<http://www2.uol.com.br/omossoroense/2502/entrevista.htm> Acesso em: 28 jun. 2014.

DIAS, Roberto Barros. "DEUS E A PÁTRIA": Igreja e Estado no processo de Romanização na Paraíba (1894-1930). 2008. 204 f. Dissertação (Mestrado em História) - Universidade Federal da Paraíba. João Pessoa.

GATTI JÚNIOR, Décio. Apontamentos sobre a pesquisa histórico-educacional no campo das Instituições Escolares. Cadernos de História da Educação, Uberlândia, v. 1, n. 1, p. 29-31, jan./dez. 2002.

JULIA, Dominique. A cultura escolar como objeto histórico. Revista Brasileira de História da Educação, Maringá, n. 1, p. 9-41, jan./jun. 2001. 
KULESZA, Wojciech Andrzej. Igreja e educação na Primeira República. In: REUNIÃO DA ASSOCIAÇÃO NACIONAL DE PÓS-GRADUAÇÃO E PESQUISA EM EDUCAÇÃO, 25, 2002, Caxambu. Disponível em: <http://25reuniao.anped.org.br/tp25.htm\#gt2>. Acesso em: 13 nov. 2015.

MAGALHÃES, Justino. Contributo para a história das instituições educativas - entre a memória e o arquivo. In: FERNANDES, Rogério e MAGALHÃES, Justino (Org.). Para a história do ensino liceal em Portugal - Actas dos Colóquios do I Centenário da Reforma de Jaime Moniz (18941895). Braga: Universidade do Minho, 1999, p. 63-77.

MESQUIDA, Peri. Educação e hegemonia católica no Brasil (1870 a 1900). Diálogo Educacional, v. 2, n. 3, p. 113-128, jan./jun.2001.

MESQUIDA, Peri; LORENZETTI, Altair A. O papel atribuído à educação no processo de romanização do aparelho religioso católico. Caderno de Pós-graduação em Educação, v. 8, n. 1, p. 59-67, jun. 2001.

MONTEIRO, Denise Matos. Introdução à história do Rio Grande do Norte. Natal: Ed. UFRN, 2000.

MOURA, Wilson Bezerra. Mossoró: fatos e gente que fizeram a sua história. Mossoró: Fundação Vingt-un Rosado/Coleção Mossoroense, 1995.

NAGLE, Jorge. Educação e sociedade na Primeira República. 3. ed. São Paulo: Ed. USP, 2009.

NONATO, Raimundo. Negociantes \& mercadores: Mossoró e suas velhas firmas. Natal: Sebo Vermelho, 2010.

NOSELLA, Paolo; BUFFA, Ester. Instituições escolares: por que e como pesquisar. 2. ed. Campinas: Alínea, 2013.

OLIVEIRA, Lúcia Helena M. M. O projeto romanizador no final do século XIX: a expansão das instituições escolares confessionais. Revista HISTEDBR On-line, Campinas, n. 40, p. 145-163, dez. 2010.

OS MESTRES DA EDUCAÇÃO NA TERRA DA LIBERDADE. Correio da Tarde, Natal/Mossoró, dez. 2007. (Caderno Correio da Educação, n. 6, p. 4-5).

PINHEIRO, Karisa Lorena. C. B. O processo de urbanização da cidade de Mossoró. Natal: Editora do CEFETRN, 2007.

ROCHA, Aristotelina Pereira B. Expansão urbana de Mossoró (período de 1980 a 2004): geografia, dinâmica e reestruração do território. Natal: Ed. UFRN, 2005.

SAVIANI, Dermeval. História das ideias pedagógicas no Brasil. 3. ed. Campinas: Editores Associados, 2010.

SOUSA, Aécio Cândido de. Vingt-un Rosado: a história de uma visão liberal do desenvolvimento de Mossoró. In: FELIPE, José Lacerda A. (Org.). Vingt-un, o intelectual e o cidadão. Natal: Ed. UFRN, 2004. p. 25-43.

SOUZA, Francisco Fausto de. História de Mossoró. Mossoró-RN: Fundação Vingt-un Rosado/Coleção Mossoroense, 2010. 
SOUZA, Itamar de; MEDEIROS FILHO, João. Os degredados filhos da seca. Petrópolis: Vozes, 1984.

Recebido em: 22/12/2015

Aceito em: 04/07/2016 